\title{
Earwigs from Brazilian caves, with notes on the taxonomic and nomenclatural problems of the Dermaptera (Insecta)
}

\author{
Yoshitaka Kamimura', Rodrigo L. Ferreira² \\ I Department of Biology, Keio University, 4-1-1 Hiyoshi, Yokohama 223-8521, Japan 2 Center of Studies in \\ Subterranean Biology, Biology Department, Federal University of Lavras, CEP 37200-000 Lavras (MG), Brazil \\ Corresponding author: Yoshitaka Kamimura (kamimura@fbc.keio.ac.jp)
}

Academic editor: Y. Mutafchiev | Received 17 July 2017 | Accepted 19 September 2017 | Published 2 November 2017

http://zoobank.org/1552B2A9-DC99-4845-92CF-E68920C8427E

Citation: Kamimura Y, Ferreira RL (2017) Earwigs from Brazilian caves, with notes on the taxonomic and nomenclatural problems of the Dermaptera (Insecta). ZooKeys 713: 25-52. https://doi.org/10.3897/zookeys.713.15118

\begin{abstract}
Based on samples collected during surveys of Brazilian cave fauna, seven earwig species are reported: $C y$ lindrogaster cavernicola Kamimura, sp. n., Cylindrogaster sp. 1, Cylindrogaster sp. 2, Euborellia janeirensis, Euborellia brasiliensis, Paralabellula dorsalis, and Doru luteipes, as well as four species identified to the (sub) family level. To date, C. cavernicola Kamimura, sp. n. has been recorded only from cave habitats (but near entrances), whereas the other four organisms identified at the species level have also been recorded from non-cave habitats. Wings and female genital structures of Cylindrogaster spp. (Cylindrogastrinae) are examined for the first time. The genital traits, including the gonapophyses of the $8^{\text {th }}$ abdominal segment shorter than those of the $9^{\text {th }}$ segement, and venation of the hind wings of Cylindrogastrinae correspond to those of the members of Diplatyidae and not to Pygidicranidae. This is the first synopsis of cave-dwelling earwigs of Brazil, one of the most species-rich areas of Dermaptera in the world.
\end{abstract}

\section{Keywords}

bat guano, cave fauna, Cylindrogaster cavernicola sp. n., Cylindrogastrinae, dermapteran taxonomy, female genitalia, Heterolabis, new synonym, traumatic mating

Copyright Y. Kamimura, R.L. Ferreira. This is an open access article distributed under the terms of the Creative Commons Attribution License (CC BY 4.0), which permits unrestricted use, distribution, and reproduction in any medium, provided the original author and source are credited. 


\section{Introduction}

Dermaptera (earwigs) is a polyneopteran insect order with more than 2000 described species from mainly tropical and warm temperate regions (Popham 2000; Grimaldi and Engel 2005; Haas et al. 2012). Although many dermapteran families have circumtropical distributions (Popham 2000), faunal, taxonomic, and ecological studies are scarce for tropical or subtropical species, especially the cave-dwelling species.

Organisms that live in the subterranean environments are frequently classified into three categories (e.g., Souza-Silva et al. 2011): i) trogloxenes - species occasionally found in caves or using the caves as nighttime or daytime shelters; ii) troglophiles that could complete their whole life cycle inside or outside the caves; and iii) trogolobites species that do not occur in epigean habitats and exhibit behavioral, morphological and physiological specializations for exclusive survival within caves.

Only two troglobitic earwigs have been reported to date: Anisolabis howarthi Brindle, 1980 (Anisolabididae) of Hawaiian lava caves and Anataelia troglobia Martín and Oromi, 1988 (Pygidicranidae) of a lava cave in La Palma, Canary Islands. These species exhibit the characteristics of true cavernicolous insects, including reduced, apparently non-functional compound eyes, slender appendages, and a less-pigmented integument (Brindle 1980a; Martín and Oromi 1988). The genus Anataelia is endemic to the Canary Islands and the other two species, A. canariensis Bolivar, 1899 and A. lavicola Martín \& Oromi, 1988, have well-developed eyes and are found both in subterranean and in epigean habitats (Ashmole and Ashmole 1987; Ashmole et al. 1992).

Haplodiplatys milloti (Chopard, 1940) (Haplodiplatyidae), which has been exclusively reported from an entirely dark part of an African cave, has well-developed compound eyes, while the integument is pale and the appendages are slenderer than in related species (Chopard 1940). It is estimated that this species recently adapted to cave life and has experienced minimal morphological changes (Brindle 1980a). Similarly, Challia phoenix Anisyutkin \& Gorokhov, 1998 (Pygidicranidae sensu stricto) was described based on a single male specimen collected from a cave of Vietnam. Although its relationships to the cave habitat is unclear, according to the descriptions by Anisyutkin and Gorokhov (1998), this species shows no sign of reduction in the compound eye.

Conversely, eyeless earwigs do not necessarily occur in caves. Anophthalmolabis spp. (Anisolabididae) (Brindle 1968; Peck 1990) and Caecolabia gomyi Brindle, 1975 (Spongiphoridae) (Brindle 1975), are eyeless but usually found from soils. Peck (1990) reported that Anophthalmolabis leleupi Brindle, 1968, which is endemic to the Galapagos Islands, also occurs in caves (possibly troglophilic).

Members of the family Arixeniidae are also considered trogrophilic. These species are phoretic on bats (Cheiromeles torquatus Horsfield, 1824) or are found on bat guano (Nakata and Maa 1974; Marshall 1977). However, as the bat hosts roost in caves and tree hollows, arixeniids are not categorized as true cavernicolous animals. Nevertheless, 
they have reduced compound eyes as an adaptation to dark habitats (e.g., Nakata and Maa 1974). Similarly, in members of the Hemimeridae, which are phoretic on African tunnel-living giant rats (Cricetomys spp.), eyes are entirely absent (e.g., Nakata and Maa 1974). Morphological and molecular phylogenetic studies showed that both Hemimeridae and Arixeniidae are specialized in-groups of the superfamily Forficuloidea that also includes free-living earwigs of the families Spongiphoridae, Chelisochidae, and Forficulidae (Klass 2001; Haas and Klass 2003; Jarvis et al. 2005; Tworzydlo et al. 2013; Kocarek et al. 2013; Naegle et al. 2016).

Most earwigs found in caves are considered troglophiles that show no apparent specialization for life in dark environments (Chopard 1921, 1924; Brindle 1980a). Examples include Chelisoches morio (Fabricius, 1775) (Chelisochidae) and Schizochelisoches brevipennis (Borelli, 1923) (Chelisochidae) of Malaysian caves (Chopard 1929; McClure et al. 1967), and Carcinophora americana (Palisot de Beauvois, 1817) of Puerto Rican caves (Peck 1974).

As one of the most species-rich areas in the world, approximately 150 species of earwigs have been reported from Brazil (Haas 2012). Nevertheless, except for some rare mentions of Dermaptera in cave environments (Pinto-da-Rocha 1995), no comprehensive review has been reported for cave dermapteran fauna of this country. As an attempt to fill this gap, this is the first synopsis of Brazilian cave-dwelling earwig. Based on the samples collected during surveys of Brazilian cave fauna, we report seven earwig species from cave habitats for the first time. Wing and genital structures are described for some species, based on which we discuss their classification, ecology, and behavior.

\section{Materials and methods}

The 93 dermapteran specimens examined in this study were collected from 2000 to 2015 during surveys of Brazilian cave fauna. All samples were collected manually. Most caves were visited only once in the inventories of subterranean invertebrates conducted in different research projects. Several samples were collected by consulting companies or governmental institutions (ATIVO AMBIENTAL, CARSTE, SPELAYON, or CECAV), for which detailed environmental conditions of the locality are unknown.

All samples were preserved in $70 \%$ ethanol after collection, and therefore the body color of some specimens was bleached. To examine wing and genital structures, several adult samples were dried after mounting on cardboard using fish glue. Genitalia were removed from specimens, mounted in Euparal (Waldeck GmbH and Co. KG, Münster, Germany) between two coverslips, and attached to the pin of the respective specimen.

All of the samples examined in this study have been deposited in the Subterranean Invertebrate Collection of Lavras (ISLA), of the Universidade Federal de Lavras 
(UFLA), Lavras, Brazil, with assignment of sample numbers shown in parentheses below, with the exception of some comparative samples from other depositories.

We follow Engel and Haas (2007) for the suprageneric classification, except for the subfamily Cylindrogastrinae which we considered to belong in Diplatyidae (see below). In addition, Engel et al. (2017) proposed to move the genus Haplodiplatys, which is considered the oldest offshoot of the extant Dermaptera (Haas 1995; Hass and Kukalová-Peck 2001; Hass and Klass 2003), from Diplatyidae to Haplodiplatyidae Engel, 2017. We follow this view. The generic classification follows that of Steinmann (1986, 1989a, 1989b, 1990, 1993) unless otherwise noted. The terminologies of Hass and Kukalová-Peck (2001), Klass (2003), and Kamimura (2014) were used for wing, female genital, and male genital structures, respectively.

\section{Abbreviations}

$\begin{array}{ll}\text { Male genitalia } \\ \text { dp } & \text { denticulated pad } \\ \text { ho } & \text { horn } \\ \text { pm } & \text { paramere } \\ \text { rsc } & \text { rectangular sclerite } \\ \text { tp } & \text { toothed plate } \\ \text { vg } & \text { virga } \\ & \\ \text { Female } & \text { genitalia } \\ \text { ap } & \text { anal plate } \\ \text { g19 } & \text { gonoplac (=coxal lobe) IX } \\ \text { gp8 } & \text { gonapophysis VIII } \\ \text { gp9 } & \text { gonapophysis IX } \\ \text { lp } & \text { lateral plate } \\ \text { sa } & \text { spined area } \\ \text { sp } & \text { spermatheca } \\ \text { tg10 } & \text { tergum X }\end{array}$

Wing structures

AA3 anal anterior 3
AA4 anal anterior 4
AP anal posterior
BAA1 +2 anal anterior $1+2$ basivenale (anal brace)
BAA3+4 anal anterior $3+4$ basivenale
C costa
CuA cubitus anterior
CuP cubitus posterior
FAJ anojugal fulcalare
JA jugal anterior

\section{Depositories}

ISLA Invertebrados Subterrâneos de Lavras (Subterranean Invertebrates, Lavras) of UFLA

MM Manchester Museum, UK

OMNH Osaka Museum of Natural History, Japan

UFLA Federal University of Lavras, Brazil

YK personal collection of Y. K.

\section{Results and remarks}

Apart from Cylindrogaster, for which a new species is described, eight organisms were recorded in this study; however, only four were determined to the species level, while four were determined to the (sub) family level. 
Order DERMAPTERA de Geer, 1773

Infraorder PROTODERMAPTERA Zacher, 1910

Family DIPLATYIDAE Verhoeff, 1902

Subfamily CYLINDROGASTRINAE Maccagno, 1929

Cylindrogaster Stål, 1855

Cylindrogaster cavernicola Kamimura, sp. $\mathbf{n}$.

http://zoobank.org/CDD2C2A8-007B-4BF5-BCB7-B2C39D2427AC

Figs $1-7$

Material examined. Holotype $\widehat{\widehat{O}}$, 'Gruta Apertar $\mid$ da Hora $\mid$ Jandaíra RN <= Rio Grande do Norte>', 'ISLA | 21101', '15.ii.2010 | Ferreira, R.L. leg.', 'HOLOTYPE (male) $\mid$ Cylindrogaster cavernicola | sp. n. | Det. Y. Kamimura 2017’.

Diagnosis. Cylindrogaster cavernicola sp. n. is a median-sized species with a slender abdomen and simple forceps. This species differs from all other species of Cylindrogaster with the combination of the following characters: the well-developed tegmina; pronotum slightly longer than broad; parameres with blunt apices; and short but weakly sinuated virgae.

Description. Male (holotype: Fig. 1). Length of body (without forceps): $11 \mathrm{~mm}$. Length of forceps: $1.4 \mathrm{~mm}$. Head width: $1.5 \mathrm{~mm}$. Pronotum width: $1.0 \mathrm{~mm}$. Pronotum length: $1.3 \mathrm{~mm}$.

The body color of the holotype seems to have been bleached by preservation in ethanol. Body color uniformly pale amber but abdomen darker. Body, including forceps, sparsely pubescent.

Head (Fig. 2) slightly longer than broad, widest in the region of the eyes; frons tumid, occiput depressed; transverse and median suture not conspicuous but visible; hind margin strongly emarginated in middle; post-ocular carina well developed, almost straight, running from middle of the internal margin of the eyes to the hind margin of the head; lateral margins of post-ocular region bordered with strong bristles. Antennae broken, 10 (right) and 15 (left) segments remaining; first segment stout, expanded apically, length almost the same as the distance between antennal bases; second segment short, quadrate; third segment expanding apically, widest width almost the same as the length; fourth segment almost quadrate; fifth segment almost quadrate (left side) to 1.5 times longer than the width (right side); remaining segments gradually lengthening. Eyes prominent, slightly shorter than post-ocular length. Pronotum (Fig. 2) slightly longer than broad; anterior margin almost straight; sides parallel; hind margin broadly rounded; median sulcus distinct; prozona weakly raised. Tegmina (Fig. 3) well developed, 1.5 times wider than pronotum, about twice as long as pronotum; broad triangular scutellum visible. Wings (Fig. 3) well-developed. Legs long, slender; hind tarsi with first segment 2.5 times longer than third, second segment about half as long as third, claw with small arolium. Abdomen long, cylindrical; segments eight and nine slightly expanded. Penultimate $\left(=9^{\text {th }}\right)$ sternite (Fig. 4) slender, with shallow concave sides; caudal margin forming 

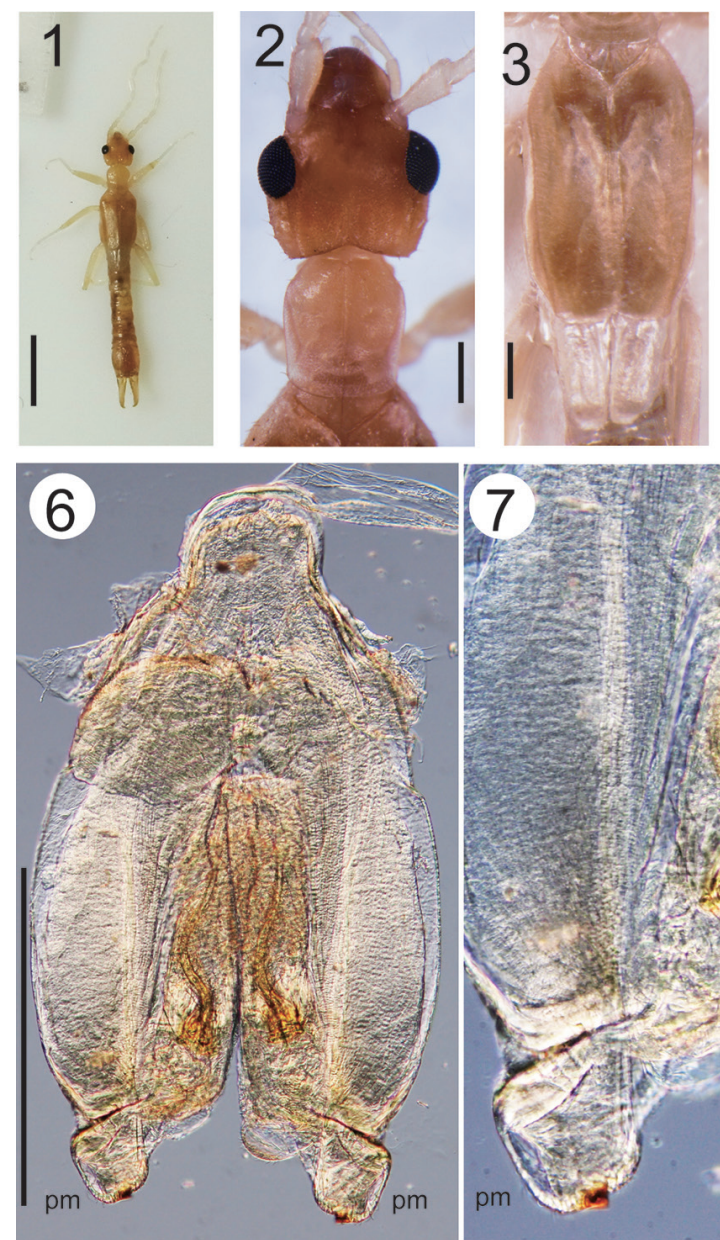
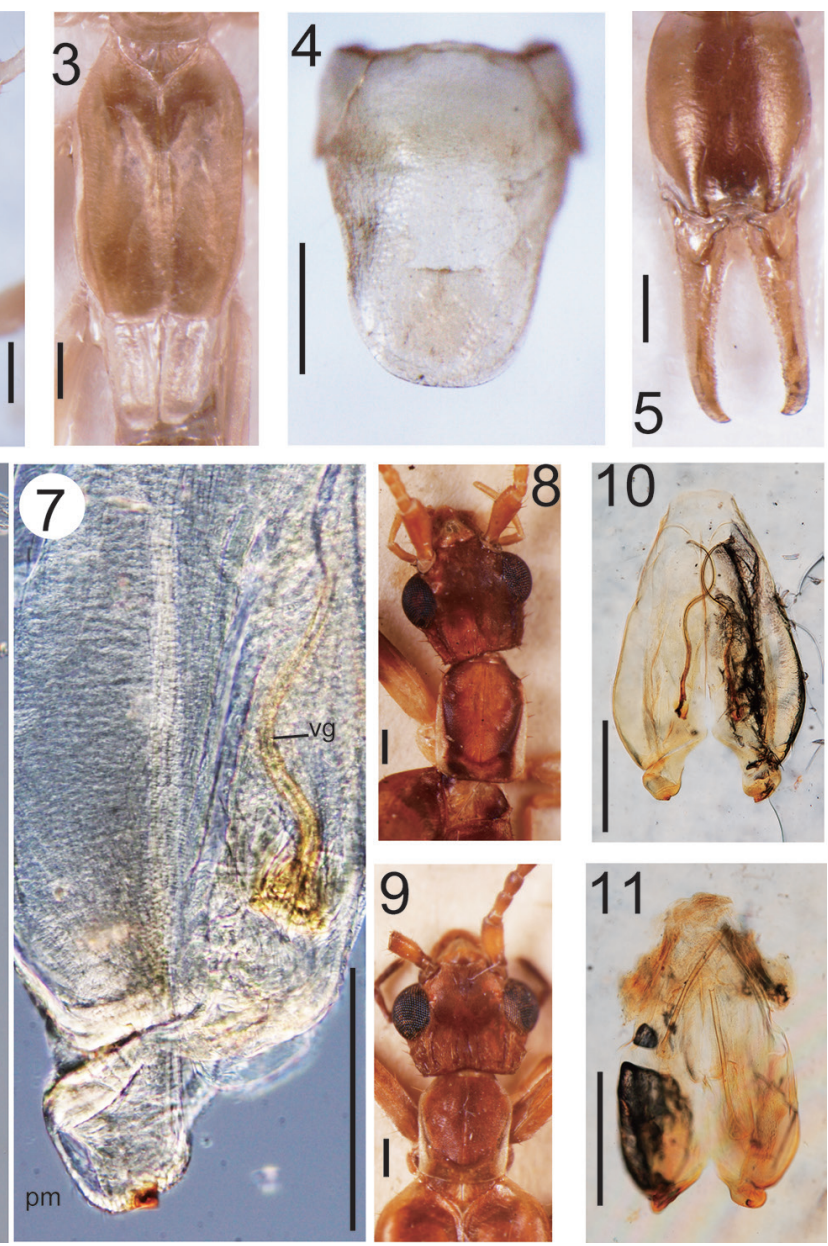

Figures I-I I. I-7 Cylindrogaster cavernicola Kamimura, sp. n. (male, holotype): habitus (I), head and thorax (2), tegmina and wings (3), penultimate sternite (4), ultimate tergite and forceps (5), and genitalia $(\mathbf{6 , 7}$ ) 8, 10 Cylindrogaster thoracicus (MM 3637; collected from Itatiaia, Brazil; det. W. D. Hincks): head and thorax (8), and genitalia (10) 9, I I Cylindrogaster gracilis: head and thorax (9: MM 3677; collected from Itatiaia, Brazil; det. W. D. Hincks), and genitalia (I I : MM 3565; collected from Minas Gerais, Brazil; det. W. D. Hincks). Scale bars 3 mm for Fig. I; 0.5 mm for Figs 2-6, 8-I I; $200 \mu \mathrm{m}$ for Fig. 7.

a more or less semicircular lobe. Ultimate $\left(=10^{\text {th }}\right)$ tergite (Fig. 5) moderately inflated, oval; caudal margin shallow concave between forceps. Forceps (Fig. 5) robust and short, almost straight, pubescent especially on inner margins, tapering and weakly curving inward apically, base of inner margin with small tooth. Genitalia (Figs 6, 7); virga short and sinuated; parameres (= external parameres) short and broad, rounded, with small triangular sclerotized tubercle and sparse short hairs at apex.

Female. Unknown.

Remarks. The subfamily Cylindrogastrinae consists of six species belonging to the Neotropical genus Cylindrogaster (Hincks 1955; Steinmann 1986, 1989b). Their 
external appearance resembles those of the Diplatyinae species or Diplatyidae sensu stricto (Table 1). However, males of Cylindrogaster spp., including C. cavernicola sp. n. described here, have one gonopore on each of the paired virgae, which is a heavily sclerotized process containing the terminal part of the ejaculatory duct, whereas male diplatyids (and haplodiplatyids) have a pair of bifurcated virgae (Hincks 1955; Steinmann 1989a).

This new species is allied to $C$. gracilis Stal, 1855, which was recorded from Brazil (and also possibly from Peru). However, the virga is entirely straight and the parameres are much wider than the length in the latter species (Fig. 11). Another Brazilian species, C. thoracicus Dohrn, 1863, can be distinguished from C. cavernicola sp. n. by its much longer virgae (Fig. 10) and pronotum (Fig. 8).

\section{Key to the known Cylindrogaster species (males only)}

1 Tegmina reduced to small lateral flaps. Ultimate tergite strongly inflated. Forceps well developed, so-called macrolabic. Cylindrogaster bicyclurus

- $\quad$ Tegmina not reduced, well developed, normal. Ultimate tergite not or little inflated. Forceps, so-called microlabic ............................................. 2

$2 \quad$ Parameres of genitalia triangular with pointed apex .............................. 3

- $\quad$ Parameres of genitalia trapezoid or oval, broader than long, with blunt apex..... 4

3 Virga short but sinuated, with a characteristic projection at middle

Cylindrogaster sablbergi

- Virga short, curved but not sinuated, without a characteristic projection at the middle

Cylindrogaster yepezi

4 Pronotum (excluding anterior zone tapering to head) apparently longer than broad (Fig. 8) ........................................................................ 5

- $\quad$ Pronotum (excluding anterior zone tapering to head) almost quadrate or slightly longer than broad (Figs 2, 9) .............................................6

5 Pronotum (excluding anterior tapering region) more than 1.5 times longer than broad. Virga straight, very short, almost half as long as penis lobe

Cylindrogaster velox

- $\quad$ Pronotum (excluding anterior tapering region) less than 1.5 times longer than broad. Virga sinuated, relatively long (Fig. 10)

Cylindrogaster thoracicus

Virga simple, straight, almost as long as penis lobe (Fig. 11)

Cylindrogaster gracilis

Virga very short, almost half as long as penis lobe, but weakly sinuated (Figs $6,7)$

Cylindrogaster cavernicola Kamimura, sp. n.

Etymology. The species epithet refers to the cave-dwelling habit of this new species, although it is presently unknown whether it is a troglobite.

Distribution. Rio Grande do Norte, Brazil. 
Table I. Proposed classification systems for the infraorder Protodermaptera Zacher, 1910.

\begin{tabular}{|c|c|c|c|c|c|}
\hline $\begin{array}{c}\text { Hincks } \\
(1955,1959)\end{array}$ & Popham (1985) & $\begin{array}{c}\text { Steinmann } \\
(1986,1989 b)\end{array}$ & Sakai (1996) & $\begin{array}{c}\text { Engel and Haas } \\
(2007)\end{array}$ & This study \\
\hline Pygidicranidae & Pygidicranidae & Pygidicranidae & Pygidicranidae & Pygidicranidae & Pygidicranidae \\
\hline Anataeliinae & Anataeliinae & Anataeliinae & Anataelinae & Anataeliinae & Anataelinae \\
\hline \multirow[t]{3}{*}{ Blandicinae } & Blandicinae & Blandicinae & Blandicinae & Blandicinae & Blandicinae \\
\hline & & Brindlensiinae & Brindlensiinae & Brindlensiinae & Brindlensiinae \\
\hline & Chaliinae & Challiinae & Chaliinae & Challiinae & Chaliinae \\
\hline \multirow[t]{2}{*}{$\begin{array}{c}\text { Echinosoma- } \\
\text { tinae }\end{array}$} & Echinosomatinae & Echinosomatinae & Echinosomatinae & Echinosomatinae & Echinosomatinae \\
\hline & & & Prolabiscinae & (= Prolabiscinae) & Prolabiscinae \\
\hline Esphalmeninae & Esphalmeninae & Esphalmeninae & Esphalmeninae & Esphalmeninae & Esphalmeninae \\
\hline Pygidicraninae & Pygidicraninae & Pygidicraninae & Pygidicraninae & Pygidicraninae & Pygidicraninae \\
\hline \multirow[t]{3}{*}{ Pyragrinae } & Pyragrinae & Pyragrinae & Pyragrinae & Pyragrinae & Pyragrinae \\
\hline & & & & Diplatymorphinae & \\
\hline & & & & Cylindrogastrinae & \\
\hline \multirow[t]{3}{*}{ Karschiellinae } & Karschiellinae & Karschiellinae & Karschiellinae & Karschiellidae & Karschiellidae \\
\hline & & & & & $\begin{array}{c}\text { Haplodiplatyidae } \\
\text { (sensu Engel et al. } \\
\text { 2017) }\end{array}$ \\
\hline & & & $\begin{array}{l}\text { Diplatyidae } \\
\text { (sensu lato) }\end{array}$ & $\begin{array}{l}\text { Diplatyidae } \\
\text { (sensu stricto) }\end{array}$ & Diplatyidae \\
\hline \multirow[t]{2}{*}{ Diplatyinae } & Diplatyinae & Diplatyinae & Diplatyinae & & Diplatyinae \\
\hline & & Diplatymorphinae & (= Diplatymorphinae) & & Diplatymorphinae \\
\hline $\begin{array}{c}\text { (= Cylindrogas- } \\
\text { trinae })\end{array}$ & $\begin{array}{c}\text { (= Cylindrogas- } \\
\text { trinae) }\end{array}$ & Cylindrogastrinae & Cylindrogastrinae & & Cylindrogastrinae \\
\hline
\end{tabular}

Association with caves. The specimen of Cylindrogaster cavernicola Kamimura, sp. n. was collected near the entrance of a cave associated with limestone rocks from the Jandaíra formation (Upper Cretaceous) in northern Rio Grande do Norte state. The caves in this region are predominantly shallow, most of which present several connections with the epigean environment (usually vertical cracks in the limestone outcrops). Accordingly, many caves in the area are strongly influenced by the external environment. Even so, given the extremely dry external environment, the caves represent a more suitable habitat for many animal species, presenting more stable temperatures and higher humidity than the epigean habitat. Furthermore, although the macro-caves are more influenced by the epigean environment, they are connected to huge systems of meso-caves, comprising small passages that are much more stable.

\section{Cylindrogaster sp. 1}

Figs $12-17$

Material examined. 1 , Gruta Túneis, Lagoa Santa, Minas Gerais, 10.x.2011, Ferreira, RL leg. (ISLA 43365). 
Association with caves. The female specimen was collected near the entrance of a cave of the Sumidouro state park, located in Lagoa Santa, Minas Gerais state. Numerous nymphs presumably belonging to this species were observed throughout the years, especially on the cave walls in areas close to entrances, in the limestone caves of this region. Therefore, it is possible that this species uses the caves as a protected habitat during its development, but leaves the caves when reaching adulthood. They probably prey upon small invertebrates that are found on the walls near the entrances.

Description and remarks. In this study, two adult females of Cylindrogaster were examined. Based on differences in body size and genital structures (see below), these two females are not conspecific. The characteristics for species diagnosis have not been established for female Cylindrogaster spp. In addition, because the collection localities of both female samples (from Minas Gerais and Pará states, respectively) are quite far from the type locality of $C$. cavernicola sp. n. (Rio Grande do Norte state), these female samples are tentatively treated as Cylindrogaster sp. 1 (Figs 12-17) and Cylindrogaster sp. 2 (Figs 18-21) in this study.

Wing and female genital structures have not been reported for any members of Cylindrogaster. The female genital region of Cylindrogaster sp. 1 is characterized by having shorter gonapophysis VIII (gp8) than gonapophysis IX (gp9), which was slightly shorter than the finger-like gonoplac IX (g19) (Figs 15-17).

The spermatheca of Cylindrogaster sp. 1 consisted of long thin tubes (Fig. 17) without sclerotized or pigmented spermathecal capsules. In the infraorder Protodermaptera (= Pygidicranidae sensu lato or sometimes referred to as basal dermapterans), the number of spermatheca and internal branches vary both inter- and intraspecifically (Popham 1965a; Klass 2003; Kamimura 2004). However, poor specimen quality prevented characterization of the Cylindrogaster sp. 1 spermatheca.

According to Hass and Kukalová-Peck (2001), Diplatyidae (Diplatys) and Haplodiplatyidae (Haplodiplatys) are separated from other members of the infraorder Protodermaptera by the presence of (1) a narrow, slender, and elongated fustis head, (2) a long and slender costal area, (3) a concave and strongly three-dimensional anojugal arm (FAJ: anojugal fulcalare), (4) the distal end of $\mathrm{CuA} 3+4$ (cubitus anterior 3 and 4) lying between the 8 th and 9th branches of AP1+2 (anal posterior 1 and 2), and (5) two proximal branches of AP1 +2 diverging close together. The characteristics unique to Diplatyidae and Haplodiplatyidae (1-3) were observed in Cylindrogaster sp. 1 (Fig. 14). The latter two traits were not observed as the poor quality of the specimen prevented opening of the wings.

The genus Haplodiplatys (Haplodiplatyidae) is characterized by multiple plesiomorphic features, including laterally symmetrical tegmina and absence of a spiny ridge (a component of the tegmina-locking device) on the dorsal side of the mesothorax (Hass and Kukalová-Peck 2001). The female sample of Cylindrogaster sp. 1, however, possessed well-developed spiny ridges (Fig. 13), similar to those in Diplatys spp. (Diplatyidae). 

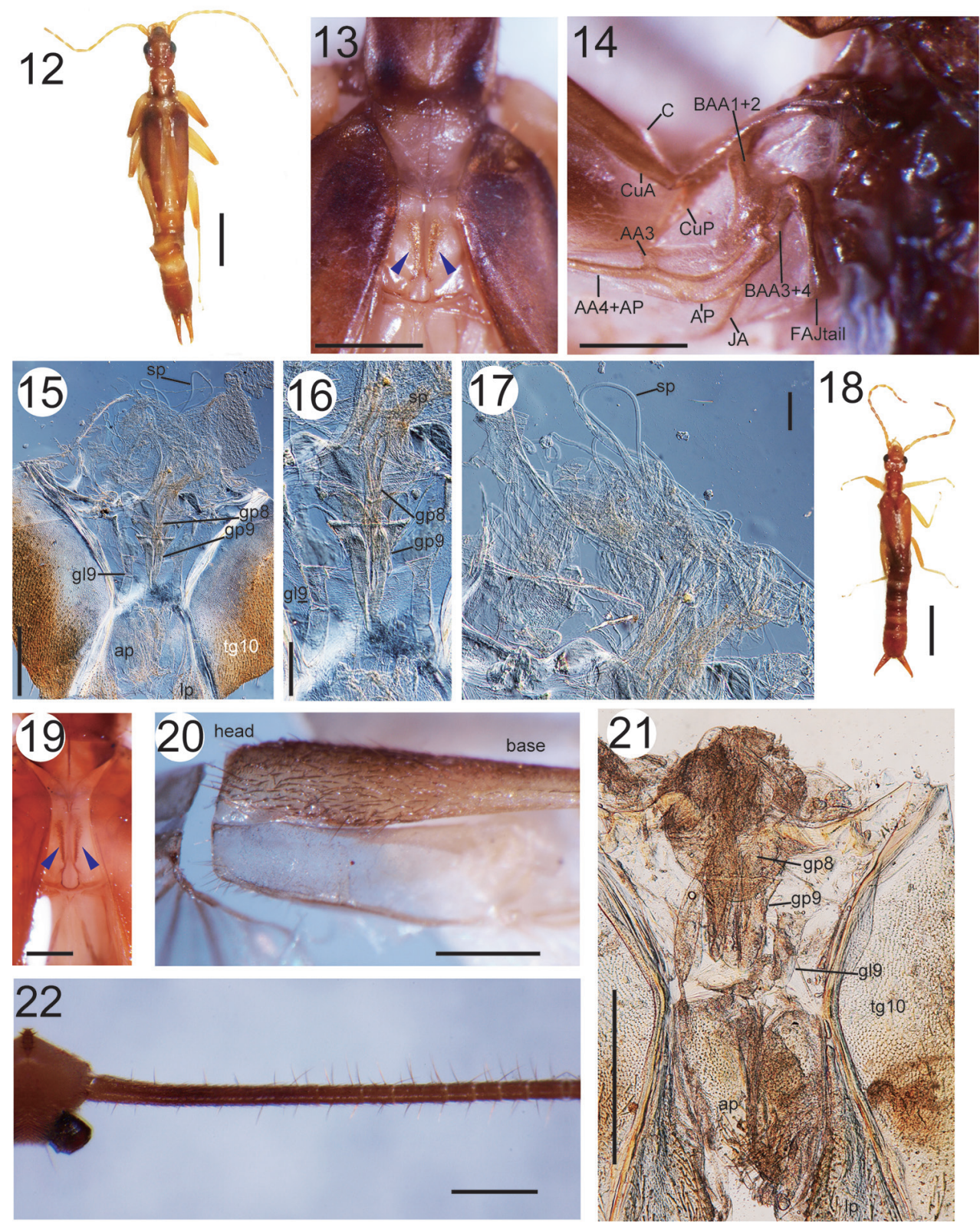

Figures I 2-22. I 2-I7 Cylindrogaster sp. 1 (female): habitus (I2), spiny ridges (indicated by the blue arrowheads) on the mesothorax (13), wing base of the left hindwing (14), and genital regions (I5-17) | 8-2 I Cylindrogaster sp. 2 (female): habitus (I8), spiny ridges (indicated by the blue arrowheads) on the mesothorax (19), fustis of the left hindwing (20), and genital regions (2I) 22 Cylindrogaster sp. (nymph): detail of cercus. Scale bars $3 \mathrm{~mm}$ for Figs I 2, I 8; $0.5 \mathrm{~mm}$ for Figs I 3-I 5, 1 9-22; $200 \mu \mathrm{m}$ for Figs I 6, I 7. 


\section{Cylindrogaster sp. 2}

Figs $18-21$

Material examined. 1 , , Cave N5SM1-017, Parauapebas, Pará, 17.ii.2011, CARSTE leg. (ISLA 15558).

Association with caves. The specimen was found in the cave N5SM1-017 (also known as GEM-1190 cave). This cave consists of a shallow iron ore cave (14 m horizontal projection), located in Carajás region (Pará state, Brazil). The surrounding vegetation is composed of Amazon forest with a dense canopy. The cave has only one wide and shaded entrance, with the presence of vegetation (lichens, moss, and ferns). Furthermore, it does not present an aphotic zone, being lightened throughout its whole extension. The litter is abundant near the entrance zone and sparse in the rest of the cavity. Several caves were sampled in this region, and as a single specimen was found, it is likely that this species is accidental or seeks only temporarily shelter in caves.

Description and remarks. The genital structures of this species are essentially similar to those of Cylindrogaster sp. 1, but the spermatheca was missing likely due to incorrect dissection. Cylindrogaster sp. 2 differs from Cylindrogaster sp. 1 in having triangular shaped g19 (Fig. 21) vs. finger-like in Cylindrogaster sp. 1 (Figs 15, 16), as well as a much smaller body size (Fig. 18 vs. 12). The wing and mesothoracic structures of Cylindrogaster sp. 2 were basically the same as those of Cylindrogaster sp. 1. Refer to Figures 19 and 20 for images of the spiny ridges and fustis, respectively.

\section{Cylindrogaster species}

Fig. 22

Material examined. 1 nymph, Cavidade RF 86, Barão de Cocais, Minas Gerais, 9.ii.2015, ATIVO AMBIENTAL leg. (ISLA 15507) - 1 nymph, Cavidade CBT_09, Barão de Cocais, Minas Gerais, 19.i.2015, ATIVO AMBIENTAL leg. (ISLA 15508) - 1 nymph, S11D, S11D-0003, Serra / Sul, Canaã dos Carajás, Pará, 16.xii.2014, CARSTE leg. (ISLA 17201) - 1 nymph, Gruta da Lapinha, Lagoa Santa, Minas Gerais, 7.vii.2011, Ferreira, RL leg. (ISLA 21083) - 3 nymphs, Cave GEM-1194, Parauapebas, Pará, 23.ii.2011, CARSTE leg. (ISLA 21087) - 1 nymph, CAPA 03, Itabirito, Minas Gerais, 11.xi.2013, SPELAYON leg. (ISLA 21088) - 1 nymph, Cave Mll GEM-1705, Parauapebas, Pará, 13.iv.2011, CARSTE leg. (ISLA 21091) - 2 nymphs, Cave Mll GEM-1738, Parauapebas, Pará, 3.xi.2011, CARSTE leg. (ISLA 21092) - 1 nymph, Cave Mll GEM-1694, Parauapebas, Pará, 20.iii.2011, CARSTE leg. (ISLA 21095) - 4 nymphs, Didi Vieira cave, Afonso Cláudio, Espírito Santo, 23.iii.2005, Souza MS et al. leg. (ISLA 21098) - 1 nymph, Sitio Paraíso cave, Ecoporanga, Espírito Santo, 22.vii.2004, Souza MS et al. leg. (ISLA 21099) - 2 nymphs, Gruta do Roxo, Novo Oriente de Minas, Minas Gerais, 20.vii.2002, Souza MS et al. leg. (ISLA 21100) - 1 nymph, SEP-0407 (Geraldo Gusso), Felipe Guerra, Rio Grande do Norte, 
2.x.2010, Ferreira, RL leg. (ISLA 21102) - 1 nymph, Lapa de Urtiga, Vazante, Minas Gerais, 16.ix.2010, Ferreira, RL leg. (ISLA 2735).

Remarks. A total of 21 nymphs of Cylindrogaster were examined. Nymphal cerci were frequently lost in these specimens, but when present, they were always segmented instead of unsegmented forceps of adults (Fig. 22).

Species diagnosis has not been established for nymphal samples of Cylindrogaster spp.

\section{Infraorder EPIDERMAPTERA Engel, 2003 Family ANISOLABIDIDAE Verhoeff, 1902 \\ Subfamily ANISOLABIDINAE Verhoeff, 1902 \\ Euborellia Burr, 1910}

\section{Euborellia janeirensis (Dohrn, 1864)}

Figs 23-28

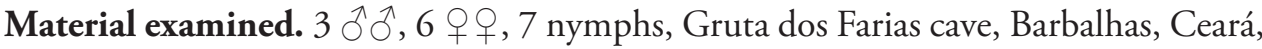
30.iv.2007, Ferreira, RL leg. (ISLA 15565) - 1 nymph, Cave GEM-1623, Parauapebas, Pará, 16.iii.2011, CARSTE leg. (ISLA 21085) - 1 nymph, Gruta Ecos cave, Cocalzinho de Goiás, Goiás, 4.iv.2006, CECAV leg. (ISLA 21096).

Association with caves. While most earwigs found in Brazilian caves seem to be accidental, this species was present as a large population within Gruta dos Farias cave, a sandstone cave located in Barbalhas municipality (Ceará state, Brazil). Many adults and nymphs were observed only in guano piles in deeper areas of the cave, which has a stream trespassing its entire conduit, strongly suggesting that the population is troglophilic. They are likely feeding on bat guano or preying upon small invertebrates.

Description and remarks. All adult specimens examined in this study had fully developed tegmina, but lacked hind wings. Four species of Euborellia from the Neotropical region, E. boliviana Brindle, 1971, E. ambigua (Borelli, 1906), E. caraibea Hebard, 1921, and E. janeirensis, also have such characteristics. Among these species, $E$. janeirensis is distinguished from the others by the presence of well-developed lateral longitudinal ridges on the male abdominal tergites VI and IX, and one or more white/ yellow distal antennal segments (Steinmann 1989a). The external morphologies and male genitalia of the specimens examined in this study agreed well with those described previously for E. janeirensis, including brown markings on the femora (Figs 23 and 27), the shapes of the forceps (Figs 23 and 27), and the shapes of the parameres and denticulated pads in the penis lobe (Fig. 26).

Taxonomists generally examine only the terminal region of the male genital organs. The male genitalia of $E$. janeirensis were approximately $22 \mathrm{~mm}$ in length, and more than twice the body length with forceps (Fig. 25). The manubrium, which is an extension in the basal, inner margin of the penultimate sternite (Burr 1915b; Ramamurthi 1958), was approximately $6 \mathrm{~mm}$ in length (Fig. 24). In male earwigs, the 

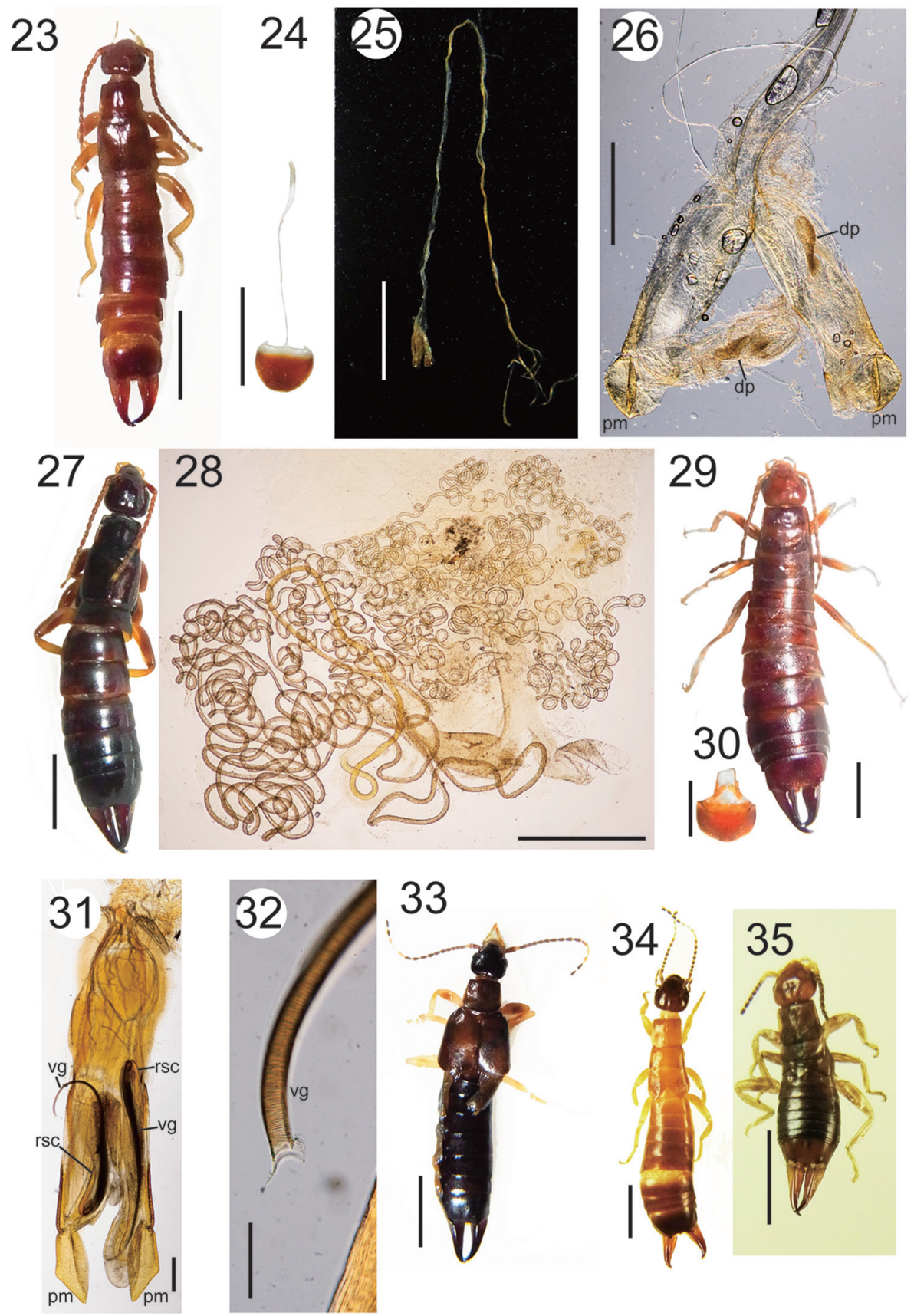

Figures 23-35. 23-26 Euborellia janeirensis (male): habitus (23), penultimate sternite + manubrium (24), and genitalia $(\mathbf{2 5}, \mathbf{2 6}) \mathbf{2 7 - 2 8}$ Euborellia janeirensis (female): habitus (27), and spermatheca (28) 29-32 Euborellia brasiliensis (male): habitus (29), penultimate sternite + manubrium (30), and genitalia $(\mathbf{3}$ I, 32) 33 Anisolabididae gen. sp. 1 (female): habitus 34 Anisolabididae gen. sp. 2 (nymph): habitus 35 Anisolabididae gen. sp. 3 (nymph) habitus. Scale bars 3 mm for Figs 23-25, 27, 29, 30, 33-35; 0.5 mm for Figs 26, 28, 3 I; $100 \mu \mathrm{m}$ for Fig. 32. 
retractor muscles of the genitalia originate from this structure (Popham 1965a). As reported by Mariani (1994), the spermatheca of this species was a long and thin blind duct lacking a capsule at the distal end (Fig. 28).

Males of Euborellia spp. directly insert the elongated virga into the female spermatheca during copulation (Kamimura 2000; Lieshout and Elgar 2011). Elongation of the virga (and the genitalia as a whole, which functions as the virgal sheath when in repose) is considered an adaptation for removal of rival sperm from the female spermatheca, which is usually longer than the virga (Kamimura 2000, 2005, 2013, 2015; Lieshout and Elgar 2011). Thus, genital elongation in E. janeirensis suggests intensive sperm competition in this species.

Distribution. Brazil, Argentina, Paraguay, and Venezuela.

\section{Euborellia brasiliensis (Borelli, 1912)}

Figs 29-32

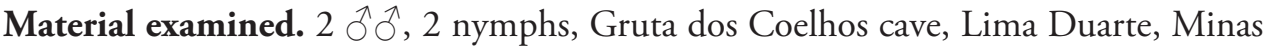
Gerais, 11.vii.2005, Ferreira, RL leg. (ISLA 15564).

Association with caves. This species was found in deeper areas (aphotic zones) of Gruta dos Coelhos and Gruta do Pião caves, both associated with quartzite rocks and located in the Ibitipoca state park (Lima Duarte municipality, Minas Gerais state, Brazil). In the latter cave, several individuals were found walking near root masses, probably searching for prey. There are several caves in the area, and at least three distinct inventories of cave fauna were performed over the last 10 years. However, this species was only found in two caves, suggesting that, although probably not accidental, their association with subterranean habitats is uncommon.

Remarks. This apterous anisolabidid species from Brazil (Fig. 29) was originally described as Heterolabis brasiliensis by Borelli (1912), as the type species of the monotypic genus Heterolabis. Popham and Brindle (1966) recognized the type species as a member of the genus Euborellia Burr, 1910 and proposed the combination Euborellia brasiliensis (Borelli, 1912) Popham \& Brindle, 1966. Therefore, they considered the generic name Heterolabis as a synonym of Euborellia. Their decision was followed by Reichardt (1968b), Sakai (1970), and Steinmann (1977, 1978).

Srivastava (1978) described a second species belonging to Heterolabis, i.e. Heterolabis punctata Srivastava, 1978. Its transfer to the genus Euborellia was proposed by Sakai (1982, 1987) and Srivastava (1999). Since the binomen Euborellia punctata was preoccupied by Euborellia punctata Borelli, 1927, they proposed the replacement names Euborellia srivastavai Sakai, 1987 and E. mindanoensis Srivastava, 1999, respectively. An alternative generic position for H. punctata was proposed by Steinmann (1989b); who recognized it as a member of the genus Epilabis Burr, 1915. Since the relevant binomen was preoccupied by Epilabis punctata Srivastava, 1976, he proposed the replacement name Epilabis harlequin Steinmann, 1989.

Currently Heterolabis Borelli, 1912 is considered a synonym of Euborellia, and the species previously considered as members of Heterolabis is as follows: 
1. Euborellia brasiliensis (Borelli, 1912): Popham and Brindle (1966)

Synonym: Heterolabis brasiliensis Borelli, 1912

2. Euborellia srivastavai Sakai, 1987

Synonyms: Heterolabis punctata Srivastava, 1978; Epilabis harlequin Steinmann, 1989 (junior objective synonym); Euborellia mindanoensis Srivastava, 1999 (junior objective synonym).

The generic name Heterolabis Borelli, 1912 is an invalid homonym of Heterolabis Kriechbaumer, 1889 (Ichneumonidae).

Distribution. Brazil.

\section{Anisolabidinae sp. 1}

Fig. 33

Material examined. 1 , , cave SERP 0100, Conceição do Mato Dentro, Minas Gerais, 26.v.2014, SPELAYON leg. (ISLA 15557).

Association with caves. Unknown.

Remarks. The tegmina and wings were fully developed (Fig. 33), and this species may belong to the genus Carcinophora Scudder, 1876.

\section{Anisolabidinae sp. 2}

Fig. 34

Material examined. 2 nymphs, Gruta Ecos cave, Cocalzinho de Goiás, Goiás, 4.iv.2006, CECAV leg. (ISLA 21097) - 1 nymph, Cave GEM-1710, Parauapebas, Pará, 14.iii.2011, CARSTE leg. (ISLA 21086) - 1 nymph, cave SERP 0100, Conceição do Mato Dentro, Minas Gerais, 26.v.2014, SPELAYON leg. (ISLA 21082).

Association with caves. Unknown.

Remarks. Four nymphs, with well-developed wing primordia and some whitish antennal segments, were examined. Being recorded from Goiás, Pará, and Minas Gerais states, this species is possibly distributed widely in Brazil. Otherwise, several species may be mixed in this tentative species.

\section{Anisolabidinae sp. 3}

Fig. 35

Material examined. 1 nymph, cave RF 103, Barão de Cocais, Minas Gerais, 16.i.2015, ATIVO AMBIENTAL leg. (ISLA 15505).

Association with caves. Unknown.

Remarks. Only one young nymphal specimen was collected. This species is characterized by a brownish stripe straddling the long axis of the compound eye. 


\section{Family SPONGIPHORIDAE Verhoeff, 1902}

\section{Spongiphoridae sp. 1}

Material examined. 1 nymph, Cave Mll GEM 1712, Parauapebas, Pará, 30.x.2011, CARSTE leg. (ISLA 21093).

Association with caves. Unknown.

Remarks. This species is tentatively assigned to the family Spongiphoridae. Only one young nymph, which lacked the post-abdomen including the forceps, was examined. The antennae are characteristically stout.

\section{Subfamily LABIINAE Burr, 1911}

Paralabellula Kevan, 1997 (= Paralabella Steinmann, 1990; see Kevan and Vickery 1997)

\section{Paralabellula dorsalis (Burmeister, 1838)}

Figs 36-42

Material examined. 2 ๙ ${ }^{\lambda}, 9+q$, 8 nymphs, Cave N5SM2-099 (= GEM-1799 cave), Parauapebas, Pará, 5.v.2011, CARSTE leg. (ISLA 15563) - 1 ㅇ, Cave N5SM2-019 (= GEM-1739 cave), Parauapebas, Pará, 31.x.2010, CARSTE leg. (ISLA 15562) 3우, Cave N5SM2-099 (= GEM-1799 cave), Parauapebas, Pará, 31.x.2010, CARSTE leg. (ISLA 15560) - 1 ô, 2 qo , 8 nymphs, Cave N5SM2-019 (= GEM-1739 cave), Parauapebas, Pará, 5.v.2011, CARSTE leg. (ISLA 15561) - 1 nymph, Cave N5SM2019 (= GEM-1739 cave), Parauapebas, Pará, 31.x.2010, CARSTE leg. (ISLA 21084) - 1 nymph, Cave N5SM2-019 (= GEM-1739 cave), Parauapebas, Pará, 5.v.2011, CARSTE leg. (ISLA 21089) - 1 nymph, Cave N5SM2-019 (= GEM-1739 cave), Parauapebas, Pará, 5.v.2011, CARSTE leg. (ISLA 21090) - 3 nymphs, Cave N5SM2019 (= GEM-1739 cave), Parauapebas, Pará, 31.x.2010, CARSTE leg. (ISLA 21094).

Association with caves. Many specimens of $P$. dorsalis were found in two iron ore caves (N5SM2-019 cave - synonym of GEM-1739 cave, and N5SM2-099 cave - synonym of GEM-1799 cave), both located in Carajás region (Pará state). These caves occur in an iron ore plateau surrounded by the Amazon forest. However, they are in an area of metallophilic savannah, a vegetation type usually found at the top of plateaus. The caves are considerably large (>100 $\mathrm{m}$ in horizontal projection) compared to other caves in the area. Although many caves were sampled in the plateau (at least 100 caves), this species was found in only these two caves, which contain huge colonies of the insectivorous bat genus Pteronotus (Pteronotus gymnonotus Wagner, 1843, in the N5SM2-019 cave and Pteronotus parnellii (Gray, 1843) in the N5SM2-099 cave). These colonies produce large guano piles, where several individuals of $P$. dorsalis were 


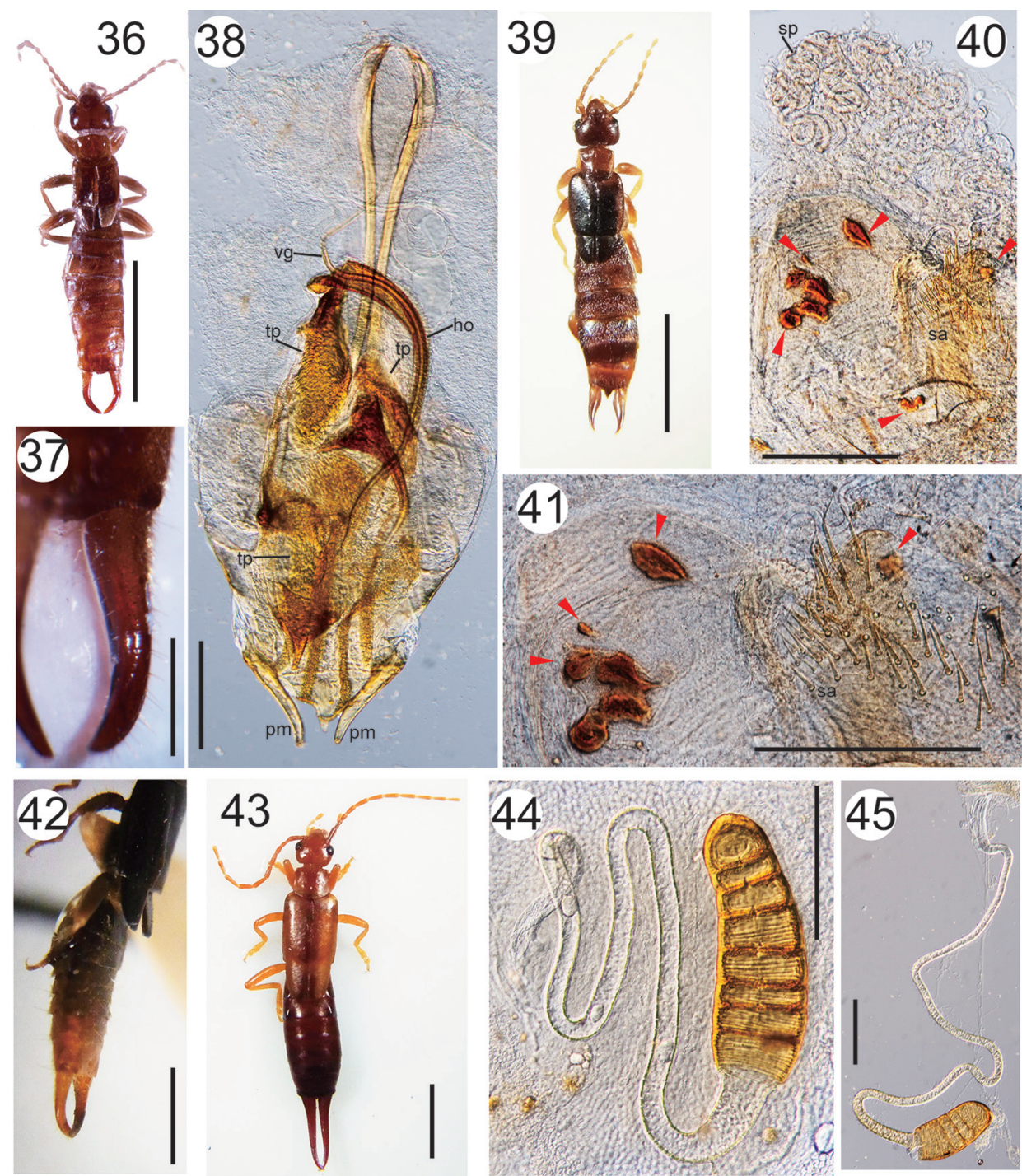

Figures 36-45. 36-38 Paralabellula dorsalis (male): habitus (36), forceps (dorsolateral view) (37), and genitalia (38) 39-4I Paralabellula dorsalis (female): habitus (39), spermatheca and spiny area in the genitalia $(\mathbf{4 0}, \mathbf{4 I})$. Repaired wound patches are indicated by the red arrowheads in Figs 40 and 41 42 Paralabellula dorsalis (male; a specimen from Colombia, det. A. Brindle; OMHH S. Sakai Collection, 31.iii.2002 [01-25]): abdomen and forceps (dorsolateral view) 43-44 Doru luteipes (female): habitus (43), and spermatheca (44) 45 Doru lineare (female; coll. Y. Kamimura, at Varzelândia, Minas Gerais, Brazil, outside of caves on 13.iii.2016): spermatheca. Scale bars $3 \mathrm{~mm}$ for Figs 36, 39, 42, 43; $0.5 \mathrm{~mm}$ for 37; $200 \mu \mathrm{m}$ for Figs 38, 40, 4I, 44, 45.

observed. The populations of $P$. dorsalis, which include both adults and nymphs, were observed in both dry and rainy seasons in the two caves, strongly suggesting that they are troglophilic. 
Description and remarks. The external morphologies and genital structures of male and female specimens were examined (Figs 36-41) and matched those of Paralabellula dorsalis (Burmeister 1838; Brunner 1906; Brindle 1971a,b,c; Steinmann 1989a; Briceño 1997; Eberhard et al. 1998). Winged and wingless morphs have been reported for a Costa Rican population of this species, where wingless individuals always predominated in the wild (Briceño and Eberhard 1987). Significantly more winged adults emerged when nymphs were subjected to low nutritional conditions (Briceño and Eberhard 1987). All adults (3 males and 13 females) examined in this study were winged morphs with fully developed tegmina and hind wings (Figs 36, 39). These findings may have been due to the poor nutritional conditions in caves. Although previous authors noted that each branch of the male forceps has a small inner tooth at the base (see Brindle 1971a, b, c; Sakai 1993), all males $(\mathrm{n}=3)$ examined in this study lacked this tooth (Fig. 37). However, one male specimen from Moniquira, Colombia, determined by A. Brindle, also lacked a tooth at the base of the forceps (Fig. 42).

Based on samples collected from Costa Rica, Briceño (1997) reported the detailed genital structures of this species, which included a horn-like structure and several heavily sclerotized toothed plates in the penis lobe. These structures were also found in the three male samples examined in this study (ho and tp, respectively, in Fig. 38). The spermatheca of this species is a long, thin, blind duct lacking a capsule at the distal end (Mariani 1994; Briceño 1997). Briceño (1997) also reported the presence of multiple fine spines around the spermathecal opening. All such features were present in the specimens examined in this study (Fig. 40, 41).

Using specimens fixed during copulation, Briceño (1997) also examined coupling of the male and female genitalia. Toothed plates were exposed by eversion of the inflated penis lobe, and contacted the inner walls of the vagina, including the spiny area. The horn-like structure functioned as a guiding sheath for the virga, potentially to facilitate insertion into the female spermatheca. There is accumulating evidence that many male animals inflict wounds on the female during mating through use of their genital structures (Lange et al. 2013; Tatarnic et al. 2014; Reinhardt et al. 2014). However, this mode of mating, termed traumatic mating, has been reported in only two species of earwigs, Echinosoma denticulatum Hincks, 1959 (Pygidicranidae: Echinosomatinae; Kamimura and Lee 2014a) and Marava arachidis (Yersin, 1860) (Spongiphoridae: Spongiphorinae; Kamimura et al. 2016b). While Briceño (1997) failed to mention the occurrence of copulatory wounding in $P$. dorsalis, melanized patches on the membranous region at the spermathecal opening were observed in this study $(\mathrm{n}=$ 2; Figs 40, 41). This finding suggests that the male genitalia cause wounding during copulation.

Distribution. West Indies, Mexico, Costa Rica, Panama and northern South America (including Brazil). 


\section{Family FORFICULIDAE Latreille, 1810 \\ Subfamily FORFICULINAE Latreille, 1810 \\ Doru Burr, 1907}

\section{Doru luteipes (Scudder, 1876)}

Figs 43, 44

Material examined. 1 क, Gruta do Vento cave, Pains, Minas Gerais, 12.x.2000, R. L. Ferreira leg. (ISLA 495) - 1 q, Gruta Zé Geraldão cave, Pains, Minas Gerais, 10.iii.2009, R. A. Zampaulo leg. (ISLA 534).

Association with caves. Doru luteipes is an extremely common species in Brazil (Reis et al. 1988), being frequently associated with crops, especially corn. The few observed specimens were found from the Pains region, which is considered the speleological area with the highest concentration of caves in Brazil (and probably in South America). Although more than 300 caves have been examined in this area (Zampaulo 2010), this species was found near the entrances of only two caves, suggesting that they are definitely accidental.

Remarks. Only female samples of Doru, which are difficult to identify to the species level, were collected in this study. The external morphologies (Fig. 43) matched those of D. luteipes (Scudder 1876; Brindle 1971d; Steinmann 1979; 1993). The females of D. luteipes are similar in appearance to Doru lineare (Eschscholtz, 1822) [Brindle 1971d; Steinmann 1979, 1993: see also Sakai 1993, 1995 for proposal of a synonymy of this species with Doru taeniatum (Dohrn, 1862)]; however, the spermathecal morphologies, including the shape of the spermathecal capsule with seven constrictions (Fig. 44: the spermathecal morphology was examined for the sample from Gruta do Vento cave), were the same as those described by Mariani (1994) for $D$. luteipes. According to Mariani (1994), the spermathecal capsule of $D$. lineare is shorter with fewer and weaker constrictions. This was confirmed in a female sample collected at Varzelândia, Minas Gerais, Brazil on 13.iii.2016 by Y.K., with conspecific males (Fig. 45). However, parthenogenesis has been reported for some Brazilian populations of $D$. lineare (Cocco et al. 2013), suggesting possible polymorphisms in the spermathecal morphology. Thus, the identification of the samples is tentative.

Distribution. Colombia, Surinam, Brazil, Peru, Bolivia, and Argentina.

\section{Discussion}

Of the five taxa identified to the species level in this study, E. brasiliensis and D. luteipes may be accidental inhabitants of caves, while $E$. janeirensis and $P$. dorsalis likely maintain permanent cave populations, but being also found in various non-cave habitats (troglophiles).

At present the association to cave habitats is unknown for $C$. cavernicola sp. $\mathrm{n}$. The species does not present any obvious troglomorphic traits. However, subterranean spe- 
cies do not always possess obvious troglomorphic traits, especially when associated with shallow subterranean habitats. Bartkowiak et al. (1991) compared the eyes of carabids with different degrees of adaptation for cave life, and suggested that troglobites living in superficial subterranean systems are able to use dim light stimuli for orientation using eyes. Some troglobitic carabids that live in shallow subterranean habitats in the Amazon with only partially reduced eyes also support this view (Pellegrini and Ferreira 2011). Accordingly, if $C$. cavernicola sp. $n$. is mainly associated with shallow subterranean habitats (such as the caves in the type locality) in the extremely dry area with high insolation, it could maintain functional eyes. Further samples and studies on the ecology of this new species are necessary, before determining whether caves are its primary habitat.

The association of Dermaptera with bat guano in caves has been reported for some species around the world: large populations of Arixenia esau Jordan, 1909 associated with bat guano piles in Niah caves, Sarawak (Medway 1958), and Xeniaria species occurring in high densities in bat guano of caves in the Gunong Mulu National Park (Borneo) (Brindle 1980b). Askew (1971) also reported Xeniaria jacobsoni (Burr, 1912) occurring in high densities in bat guano piles in a cave in Java where they prey upon small arthropods. In addition to these Arixeniids, many other species observed in caves were also collected near guano piles (Irdex chapmani Brindle, 1980 and Nala ornata Borelli, 1932 from caves in Borneo; Schizochelisoches brevipennis from caves in Peninsular Malaysia) (Brindle and Oromi 1994), suggesting that guano is an important direct or indirect resource for earwigs in caves. However, except for $E$. janeirensis and $P$. dorsalis, most species found in caves in Brazil seem to be accidental or not directly associated with guano. The reasons for this lack of association remain unknown. Additional studies are necessary to confirm the relations of Brazilian cave-dwelling earwigs to cave environments, as in most cases, only one or two samples were obtained in each cave.

\section{Systematic position of the subfamily Cylindrogastrinae}

In the present study, the wing and female genital structures are described for Cylindrogaster spp. for the first time. Well-developed ovipositor components [gonoplacs (= coxal lobes) and gonapophyses of the 8th and 9th abdominal segments (gl8, gl9, gp8, and gp9, respectively)] are considered plesiomorphic in Dermaptera (Zacher 1911; Burr 1915a; Hincks 1959; Giles 1963; Klass 2003).

Klass (2003) studied the female genitalia of almost all representative groups of the Protodermaptera (Karschellidae, Haplodiplatyidae, Diplatyidae, and Pygidicranidae sensu stricto). Many members of Pygidicranidae sensu stricto, including Echinosoma (Echinosomatinae), Dacnodes (Pygidicraninae), Tagalina (Pygidicraninae), and Anataelia (Anataelinae), are characterized by a well-developed pair of slender gp8, and a pair of long lobate gl9 that are longer than gl8 and gp9 (Klass 2003). Conversely, the gp 8 in the female genitalia of Diplatyinae (Diplatys) and Haplodiplatyidae (Haplodiplatys) is reduced and usually shorter than gl9 (Klass 2003; Kamimura et al. 2016a). This characteristic is shared with Karschiella (Karshiellidae) and Esphalmenus (Pygidicranidae 
sensu stricto, Esphalmeninae) (Klass 2003). Thus, the female genitalia of Cylindrogaster spp. are of the Diplatyinae - Karshiellidae - Esphalmenus type.

Klass (2003) also found a large unpaired gland in nearly all species. A pair of thin, long cuticular tubes (referred to as lateral tubes in Klass 2003) are associated with this gland, which opens on the midline of the body on segment IX. The only exception to this finding was Diplatys (Klass 2003). Klass (2003) noted that no similar organs have been recorded in other insect taxa, and thus the lateral tubes are likely autapomorphic for Dermaptera or for a subgroup of them. Lateral tubes have also been reported for Esphalmenus (Pygidicranidae) and Allostethus (Labiduridae sensu lato), which lack the unpaired gland (Klass 2003; Kamimura and Lee 2014b). In this study, we failed to detect an unpaired gland and lateral tubes in the female genital region of Cylindrogaster sp. 1 and Cylindrogaster sp. 2. Among the members of Protodermaptera, a similar observation was reported for Diplatys, in which only a small fold was present immediately behind the base of gonapophyses IX. It was hypothesized that the fold was a vestige of the accessory gland or of the common entrance pouch of the lateral tubes (Klass 2003).

In conclusion, multiple genital and wing traits (see "Remarks" of Cylindrogaster sp. 1 and Cylindrogaster sp. 2), as well as segmented nymphal cerci, suggested a close relationship between Cylindrogastrinae and Diplatyinae (or Diplatyidae sensu stricto). These two groups in the Protodermaptera also had depressed femora with lamelliform edges, an arolium between the claws, and short antennae with fewer than 25 segments (Hincks 1955, 1959; Steinmann 1986). The most notable difference between the two groups is the number of gonopores per virga. However, bifurcated virgae have also been reported in other groups of Pygidicranidae, including the genera Pyragra, Esphalmenus, and Cranopygia (Hincks 1959; Popham 1965a; Brindle 1984).

The subfamily Cylindrogastrinae was originally erected in the family Pygidicranidae (Maccagno 1929). The subfamily was not recognized by Hincks (1955), Popham (1965b, 1969, 1985), Reichardt (1968a) and Günther and Herter (1974) due to its similar external morphology to that of Diplatyinae (Tab. 1). However, Sakai (1971, 1982, 1985, 1996) considered the differences in the virgal morphologies (1 vs. 2 gonopores) important and recognized Cylindrogastrinae and Diplatyinae as distinct subfamilies within Diplatyidae. Steinmann $(1975,1986,1989 b)$ proposed Diplatyinae and Cylindrogastrinae as subfamilies of the family Pygidicranidae (Tab. 1). Differently, some subsequent studies placed Cylindrogastrinae within Pygidicranidae, while treating Diplatyidae at the family level (Haas and Klass 2003; Engel and Haas 2007). We support the position of Cylindrogastrinae in the Diplatyidae and not in Pygidicranidae (Tab. 1). The subfamily Diplatymorphinae includes only one species, Diplatymorpha borneensis Boeseman, 1954, which was described based on a single female specimen in Borneo (Boeseman 1954). According to Steinmann (1986), this subfamily can be separated from the Cylindrogastrinae based on the shape of fifth antennal segment: almost quadrate as the fourth segment in Diplatymorpha borneensis whereas visibly longer than the fourth segment in Cylindrogaster spp. However, as described for the holotype of Cylindrogaster cavernicola sp. n., there may be a considerable variation in the antennal morphology even within an individual. Except for the antennal morphology and 
slightly sturdier built body, the external morphology of Diplatymorpha borneensis resembles those of Diplatys species (Boeseman 1954), and therefore multiple researchers treat it as a junior synonym of Diplatyinae (Tab. 1). Accordingly, we tentatively place Diplatymorphinae as a distinct subfamily within Diplatyidae, while Diplatyidae, Haplodiplatyidae, and Pygidicranidae are treated as separate families.

\section{Acknowledgments}

We are grateful to the team of the Center of Studies in Subterranean Biology from the Federal University of Lavras (CEBS/UFLA) for their efforts in sampling earwigs in Brazilian caves. We also thank Kazunori Yoshizawa, Shigehiko Shiyake, and Dmitri V. Logunov for their help with specimen examination, Kyohei Watanabe for advice on the present status of the genus Heterolabis (Ichneumonidae), and Petr Kočárek, Christophe Girod, and Masaru Nishikawa for useful comments on a previous version of the manuscript. This study was partly supported by JSPS research grants (Kakenhi Nos. $15 \mathrm{H} 04409$ [head, Kazunori Yoshizawa] and 15K07133) to YK and CNPq grant (n.304682/2014-4 from the Conselho Nacional de Desenvolvimento Científico e Tecnológico) to RLF.

\section{References}

Anisyutkin LN, Gorokhov AV (1998) The second species of the genus Challia (Dermaptera, Pygidicranidae) from Vietnam. Zoologicheskii Zhurnal 77: 610-612. [In Russian with English abstract: translated to English in Entomological Reviews 78: 534-536.]

Ashmole MJ, Ashmole NP (1987) Arthropod communities supported by biological fallout on recent lava flows in the Canary Islands. Entomologica Scandinavica. Supplementum 32: 67-88.

Ashmole NP, Oromi P, Ashmole MJ, Martín JL (1992) Primary faunal succession in volcanic terrain: lava and cave studies on the Canary Islands. Biological Journal of the Linnean Society 46: 207-234. https://doi.org/10.1111/j.1095-8312.1992.tb00861.x

Askew RA (1971) Parasitic Insects. Heinemann Educational Books Ltd., London, 316 pp.

Bartkowiak D, Tscharntke T, Weber F (1991) Effects of stabilizing selection in the regressive evolution of compound eyes in hypogean carabid beetles. Mémoires de Biospéologie 18: 19-24.

Boeseman M (1954) The Dermaptera in the museums at Leiden and Amsterdam. Zoologische Verhandelingen, Leiden 21: 1-122.

Borelli A (1912) Dermapteres nouveaux ou peu connus du Muséum de Paris. Bulletin du Muséum National d'Histoire Maturelle, Paris 18: 221-240.

Briceño RD (1997) Genitalic structure and copulation in Paralabella dorsalis (Dermaptera: Labbidae). Revista de Biologia Tropical 45: 1107-1116.

Briceño RD, Eberhard WG (1987) Genetic and environmental effects on wing polymorphisms in two tropical earwigs (Dermaptera: Labiidae). Oecologia 74: 253-255. https://doi. org/10.1007/BF00379367 
Brindle A (1968) A new genus and species of blind Dermaptera from the Galapagos Islands. Mission Zoologique Belge aux Îles Galapagos et en Ecuador 1: 171-176.

Brindle A (1971a) The Dermaptera (earwigs) of Dominica. Smithonian Contributions to Zoology 63: 1-24. https://doi.org/10.5479/si.00810282.63

Brindle A (1971b) The Dermaptera of Caribbean. Studies on the Fauna of Curaçao and other Caribbean Islands 38: 1-75.

Brindle A (1971c) A revision of the Labiidae (Dermaptera) of the Neo-tropical and Nearctic Regions: II. Geracinae and Labiinae. Journal of Natural History 5: 155-182. http://dx.doi. org/10.1080/00222937100770101

Brindle A (1971d) A revision of the genus Doru Burr (Dermaptera, Forficulidae). Papéis Avulsos de Zoologia (São Paulo) 23: 173-196.

Brindle A (1975) Dermaptera from Reunion, with the description of a new genus and species of blind Dermaptera. Annales de la Société Entomologique de France (NS) 11: 763-766.

Brindle A (1980a) The cavernicolous fauna of Hawaiian lava tubes. 12. A new species of blind troglobiotic earwigs (Dermaptera. Carcinophoridae) with a revision of the related surfaceliving earwigs of the Hawaiian Islands. Pacific Insects 21: 261-274. http://hbs.bishopmuseum.org/pi/pdf/21(4)-261.pdf

Brindle A (1980b) Dermaptera from the Gunong Mulu National Park, Borneo. The Entomologist's Record and Journal of Variation 92: 172-175.

Brindle A (1984) The Esphalmeninae (Dermaptera: Pygidicranidae): a group of Andean and South African earwigs. Systematic Entomology 9: 281-292. https://doi. org/10.1111/j.1365-3113.1984.tb00053.x

Brindle A, Oromi P (1994) Dermaptera. In: Juberthie C, Decu V (Eds) Encyclopaedia Biospeologica. Tome I. Moulis (C.N.R.S.), Bucarest (Academie Roumaine), 289-294.

Brunner L (1906) Reports on the Orthoptera of Trinidad, West Indies. Journal of the New York Entomological Society 14: 135-165.

Burmeister H (1838) Dermatoptera. Handbuch der Entomologie, Bd 2: 743-756.

Burr M (1915a) The opisthomeres and the gonapophyses in the Dermaptera. Transactions of the Entomological Society of London 1915: 257-68.

Burr M (1915b) Note on the manubrium of the ninth sternite in the male earwig. Transactions of the Royal Entomological Society of London 1915: 269-272.

Chopard L (1921) On some cavernicolous Dermaptera and Orthoptera from Assam. Records of the Indian Museum 22: 511-527.

Chopard L (1924) On some cavernicolous Orthoptera and Dermaptera from Assam and Burma. Records of the Indian Museum 26: 81-92.

Chopard L (1929) Fauna of the Batu Caves, Selangor. XII. Orthoptera and Dermaptera. Journal of the Federated Malay States Museums 14: 366-371.

Chopard L (1940) Un remarquable Dermaptera cavernicole de l'Afrique occidentale, Diplatys milloti sp. n. Bulletin de la Société Zoologique de France 65: 75-79.

Cocco J, Butnariu AR, Bessa E, Pasini A (2013) Sex produces as numerous and long-lived offspring as parthenogenesis in a new parthenogenetic insect. Canadian Journal of Zoology 91: 187-190. https://doi.org/10.1139/cjz-2012-0289 
Eberhard WG, Huber BA, Rodriguez RL, Briceño RD, Salas I, Rodriguez V (1998) One size fits all? Relationships between the size and degree of variation in genitalia and other body parts in twenty species of insects and spiders. Evolution 52: 415-431. https://doi. org/10.1111/j.1558-5646.1998.tb01642.x

Engel MS, Haas F (2007) Family-group names for earwigs (Dermaptera). American Museum Novitates 3567: 1-20. https://doi.org/10.1206/0003-0082(2007)539[1:FNFED]2.0.CO;2

Engel MS, Huang D, Thomas JC, Cai C (2017) A new genus and species of pygidicranid earwigs from the Upper Cretaceous of southern Asia (Dermaptera: Pygidicranidae). Cretaceous Research 69: 178-183. http://dx.doi.org/10.1016/j.cretres.2016.09.009

Giles ET (1963) The comparative external morphology and affinities of the Dermaptera. Transactions of the Royal Entomological Society, London 115: 95-164. https://doi. org/10.1111/j.1365-2311.1963.tb00816.x

Grimaldi D, Engel MS (2005) Evolution of the Insects. Cambridge University Press, Cambridge, New York, 772 pp.

Günther K, Herter K (1974) Ordnung Dermaptera (Ohrwürmer). In: Helmcke J-G, Starck D, Wermuth H (Eds) Kükenthal's Handbuch der Zoologie, 2nd ed, Vol. 4, pt 2. Walter de Gruyter, Berlin, 158 pp.

Haas F (1995) The phylogeny of the Forficulina, a suborder of the Dermaptera. Systematic Entomology 20: 85-98. https://doi.org/10.1111/j.1365-3113.1995.tb00085.x

Haas F (2012) A Ordem Dermaptera. In: Rafael JA, Melo ARG, Carvalho CJB, Casari SA, Constantino R (Eds) Insetos do Brasil: diversidade e taxonomia. Holos Editora, Sao Paulo, Brazil, 297-305.

Haas F, Klass K-D (2003) The basal phylogenetic relationships in the Dermaptera. In: Klass K-D (Ed.) Proceedings of the 1st Dresden meeting on insect phylogeny: "Phylogenetic Relationships within the Insect Orders" (Dresden, September 19-21, 2003). Entomologische Abhandlungen 61: 138-142. http:/www.senckenberg.de/files/content/forschung/ publikationen/arthropodsystematics/ea_61_2/ea_61_2-119-172_klass.pdf

Haas F, Kukalová-Peck J (2001) Dermaptera hindwing structure and folding: New evidence for familial, ordinal and superordinal relationships within Neoptera (Insecta). European Journal of Entomology 98: 445-509. https://doi.org/10.14411/eje.2001.065

Haas F, Hwen JTC, Tang HB (2012) New evidence on the mechanics of wing unfolding in Dermaptera. Arthropod Systematics \& Phylogeny 70: 95-105. http://www.senckenberg. de/files/content/forschung/publikationen/arthropodsystematics/asp_70_2/03_asp_70_2_ haas_et_al_95-105.pdf

Hincks WD (1955) A systematic monograph of the Dermaptera of the world. Part I. Pygidicranidae: Diplatyinae. British Museum (Natural History), London, 132 pp.

Hincks WD (1959) A Systematic Monograph of the Dermaptera of the World. Part II. Pygidicranidae excluding Diplatyinae. British Museum (Natural History), London, 218 pp.

Jarvis KJ, Haas F, Whiting MF (2005) Phylogeny of earwigs (Insecta: Dermaptera) based on molecular and morphological evidence: reconsidering the classification of Dermaptera. Systematic Entomology 30: 442-453. https://doi.org/10.1111/j.1365-3113.2004.00276.x

Kamimura Y (2000) Possible removal of rival sperm by the elongated genitalia of the earwig, Euborellia plebeja. Zoological Science 17: 667-672. https://doi.org/10.2108/zsj.17.667 
Kamimura Y (2004) Mating behaviour and insemination in Diplatys flavicollis, an earwig with double-barreled penises and a variable number of female sperm-storage organs. Journal of Zoology 262: 37-46. https://doi.org/10.1017/S0952836903004370

Kamimura Y (2005) Last male paternity of Euborellia plebeja, an earwig with elongated genitalia and sperm removal behavior. Journal of Ethology 23: 35-41. https://doi.org/10.1007/ s10164-004-0125-3

Kamimura Y (2013) Promiscuity and elongated sperm storage organs work cooperatively as a cryptic female choice mechanism in an earwig. Animal Behaviour 85: 377-383. http:// dx.doi.org/10.1016/j.anbehav.2012.11.010

Kamimura Y (2014) Pre- and postcopulatory sexual selection and the evolution of sexually dimorphic traits in earwigs (Dermaptera). Entomological Science 17:139-166. https:// doi.org/10.1111/ens. 12058

Kamimura Y (2015) What is indirect cryptic female choice? Theoretical considerations and an example from a promiscuous earwig. In: Peretti AV, Aisenberg A (Eds) Cryptic Female Choice in Arthropods. Springer International Publishing, Switzerland, 255-283. https:// doi.org/10.1007/978-3-319-17894-3_10

Kamimura Y, Lee C-Y (2014a) Mating and genital coupling in the primitive earwig species Echinosoma denticulatum (Pygidicranidae): implications for genital evolution in dermapteran phylogeny. Arthropod Systematics and Phylogeny 72: 11-21. http://www.senckenberg. de/files/content/forschung/publikationen/arthropodsystematics/asp_72_1/02_asp_72_1_ kamimura_11-21.pdf

Kamimura Y, Lee C-Y (2014b) Genital morphology and mating behaviour of Allostethus (Dermaptera), an earwig genus of enigmatic phylogenetic position. Arthropod Systematics and Phylogeny 72: 331-343. http://www.senckenberg.de/files/content/forschung/publikationen/arthropodsystematics/asp_72_3/06_asp_72_3_kamimura_et_al_331-343.pdf

Kamimura Y, Nishikawa M, Lee C-Y (2016a) The earwig fauna (Insecta: Dermaptera) of Penang Island, Malaysia, with descriptions of two new species. Zootaxa 4084: 233-257. http://dx.doi.org/10.11646/zootaxa.4084.2.4

Kamimura Y, Tee H-S, Lee C-Y (2016b) Ovoviviparity and genital evolution: a lesson from an earwig species with coercive traumatic mating and accidental breakage of elongated intromittent organs. Biological Journal of the Linnean Society 118: 443-456. https://doi. org/10.1111/bij.12755

Kevan DKMcE, Vickery VR (1977) An annotated provisional list of non-saltatorial orthopteroid insects of Micronesia, compiled mainly from the literature. Micronesia 30: 269-353.

Klass K-D (2001) The female abdomen of the viviparous earwig Hemimerus vosseleri (Insecta: Dermaptera: Hemimeridae), with a discussion of the postgenital abdomen of Insecta. Zoological Journal of the Linnean Society 131: 251-307. https://doi.org/10.1111/j.1096-3642.2001.tb02239.x

Klass K-D (2003) The female genitalic region in basal earwigs (Insecta: Dermaptera: Pygidicranidae s.l.). Entomologische Abhandlungen 61: 173-225. http://www.senckenberg.de/files/content/forschung/publikationen/arthropodsystematics/ea_61_2/ea_61_2-173-225_klass.pdf

Kocarek P, John V, Hulva P (2013) When the body hides the ancestry: Phylogeny of morphologically modified epizoic earwigs on molecular evidence. PLoS ONE 8: e66900. https:// doi.org/10.1371/journal.pone.0066900 
Kriechbaumer J (1889) Pimpliden-Studien. 21. Entomologische Nachrichten 15: 17-24.

Lange R, Reinhardt K, Michels NK, Anthes N (2013) Functions, diversity, and evolution of traumatic mating. Biological Reviews 88: 585-601. https://doi.org/10.1111/brv.12018

van Lieshout E, Elgar MA (2011) Longer exaggerated male genitalia confer defensive spermcompetitive benefits in an earwig. Evolutionary Ecology 25: 351-362. https://doi. org/10.1007/s10682-010-9422-1

Maccagno T (1929) Dermatteri. II genera Cylindrogaster Stål. Bollettino dei Musei di Zoologia ed Anatomia Comparata della Reale Università di Torino 41: 1-15.

Mariani R (1994) Contribucion al estudio anatomico de las espermatecas en el Orden Dermaptera (Insecta). Revista de la Sociedad Entomologica Argentina 53: 79-82.

Marshall AG (1977) The earwigs (Insecta: Dermaptera) of Niah Caves, Sarawak. Sarawak Museum Journal (New Series) 25: 205-209.

Martín JL, Oromi P (1988) Dos nuevas especies de Anataelia Bol. (Dermaptera, Pygidicranidae) de cuevas y lavas recientes del Hierro y La Palma (Canarias). Mémoires de Biospéologie 15: 49-59.

McClure HE, Lim BL, Winn SE (1967) Fauna of the Dark Cave, Batu Caves, Kuala Lumpur, Malaysia. Pacific Insects 9: 399-428. http://hbs.bishopmuseum.org/pi/pdf/9(3)-399.pdf

Medway L (1958) On the habit of Arixenia esau Jordan (Dermaptera). Proceedings of the Royal Entomological Society of London (Series A) 33: 191-195. https://doi. org/10.1111/j.1365-3032.1958.tb00453.x

Naegle MA, Mugleston JD, Bybee SM, Whiting MF (2016) Reassessing the phylogenetic position of the epizoic earwigs (Insecta: Dermaptera). Molecular Phylogenetics and Evolution 100: 382-390. https://doi.org/10.1016/j.ympev.2016.03.012

Nakata S, Maa TC (1974) A review of the parasitic earwigs. Pacific Insects 16: 307-374. http:// hbs.bishopmuseum.org/pi/pdf/16(2)-307.pdf

Peck SB (1974) The invertebrate fauna of tropical American caves, part II: Puerto Rico, an ecological and zoogeographic analysis. Biotropica 6: 14-31. https://doi.org/10.2307/2989693

Peck SB (1990) Eyeless arthropods of the Galapagos Islands, Ecuador: composition and origin of the cryptozoic fauna of a young, tropical, oceanic archipelago. Biotropica 22: 366-381. https://doi.org/10.2307/2388554

Pellegrini TG, Ferreira RL (2011) Coarazuphium tapiaguassu (Coleoptera: Carabidae: Zuphiini), a new Brazilian troglobitic beetle, with ultrastructural analysis and ecological considerations. Zootaxa 3116: 47-58.

Pinto-da-Rocha R (1995) Sinopse da fauna cavernicola do Brasil (1907-1994). Papéis Avulsos de Zoologia (São Paulo) 39: 61-173.

Popham EJ (1965a) The functional morphology of the reproductive organs of the common earwig (Forficula auricularia) and other Dermaptera with reference to the natural classification of the order. Journal of Zoology 146: 1-43. https://doi.org/10.1111/j.1469-7998.1965.tb05198.x Popham EJ (1965b) A key to Dermapteran subfamilies. Entomologist, London 98: 126-136. Popham EJ (1969) Rates of evolution in the Dermaptera. Entomologist, London 102: 75-79. Popham EJ (1985) The mutual affinities of the major earwig taxa (Insecta, Dermaptera). Zeitschrift für Zoologische Systematik und Evolutionforschung 23: 199-214. https://doi. org/10.1111/j.1439-0469.1985.tb00583.x 
Popham EJ (2000) The geographical distribution of the Dermaptera (Insecta) with reference to continental drift. Journal of Natural History 34: 2007-2027. http://dx.doi. org/10.1080/00222930050144837

Popham EJ, Brindle A (1966) Genera and species of the Dermaptera. 3. Carcinophorinae and Arixenidae. Entomologist, London 99: 269-278.

Ramamurthi BN (1958) Studies on the male genital tube in the Dermaptera. Proceedings of the Royal Entomological Society of London (Series A) 33: 186-190. https://doi. org/10.1111/j.1365-3032.1958.tb00452.x

Reichardt H (1968a) Catalogue of New World Dermaptera (Insecta). Part I. Introduction and Pygidicranoidea. Papéis Avulsos de Zoologia (São Paulo) 21: 183-193.

Reichardt H (1968b) Catalogue of New World Dermaptera (Insecta). Part II. Labioides, Carcinophoridae. Papéis Avulsos de Zoologia (São Paulo) 22: 35-46.

Reinhardt K, Anthes N, Lange R (2014) Copulatory wounding and traumatic insemination. In: Rice WR, Gavrilets S (Eds) The Genetics and Biology of Sexual Conflict. Cold Spring harbor Laboratory Press, New York, 115-139.

Reis LL, Oliveira LJ, Cruz I (1988) Biologia e potencial de Doru luteipes no controle de Spodoptera frugiperda. Pesquisa Agropecuária Brasileira 23: 333-342.

Sakai S (1970) Dermapterorum Catalogus Praeliminaris. I. Labiduridae and Carcinophoridae. Daito Bunka University, Tokyo, 49 pp. and 91 pp.

Sakai S (1971) Dermapterorum Catalogus Praeliminaris III-VI. A basic survey for numerical taxonomy of the Pygidicranidae, Karschiellidae, Diplatyidae, and Chelisochidae, the Dermaptera of the World. Daito Bunka University, Tokyo, 68 pp. (III), 14 pp. (IV), 162 pp. (IV), 265 pp. (V), and 210 pp. (VI).

Sakai S (1982) A new proposed classification of the Dermaptera with special reference to the check-list of the Dermaptera of the world. Bulletin of Daito Bunka University 20: 1-108.

Sakai S (1985) Dermapterorum Catalogus XVI-XVIII: Iconographia I-III. Pygidicranidae and Diplatyidae. Daito Bunka University, Tokyo, 1080 pp.

Sakai S (1987) Dermapterorum Catalogus XIX-XX: Iconographia IV-V. Chelisochidae and Anisolabididae. Daito Bunka University, Tokyo, 1567 pp.

Sakai S (1993) Dermapterorum Catalogus XXV: Iconographia IX. Spongiphoridae III. Daito Bunka University, Tokyo, 595 pp.

Sakai S (1995) Dermapterorum Catalogus XXVIII: Iconographia XII. Forficulidae. Daito Bunka University, Tokyo, $712 \mathrm{pp}$.

Sakai S (1996) Dermapterorum Catalogus XXXI: Notes on contemporary classification of Dermaptera and recent references of Dermaptera. Daito Bunka University, Tokyo, 588 pp.

Scudder SH (1876) A century of Orthoptera. Decade V. Forficulariae (North America). Proceedings of the Boston Society of Natural History 18: 251-257.

Souza-Silva M, Martins RP, Ferreira RL (2011) Cave lithology determining the structure of the invertebrate communities in the Brazilian Atlantic Rain Forest. Biodiversity and Conservation 20: 1713-1729. https://doi.org/10.1007/s10531-011-0057-5

Srivastava GK (1978) Studies on the Dermaptera of Philippines. Eos 52: 255-307.

Srivastava GK (1999) On the higher classification of Anisolabididae (Insecta: Dermaptera) with a check-list of genera and species. Records of the Zoological Survey of India 97: 73-100. 
Steinmann H (1975) Suprageneric classification of Dermaptera. Acta Zoologica Academiae Scientiarum Hungaicae 21: 195-220.

Steinmann H (1977) A study on the higher taxa of Carcinophoridae (Dermaprera). Annales Historico-Naturales Musei Nationalis Hungarici 69: 89-99.

Steinmann H (1978) Zoogeographical dispersity of Carcinophoridae (Dermaptera). Deutsche Entomologische Zeitschrift 25: 173-189. https://doi.org/10.1002/mmnd.19780250112

Steinmann H (1979) The Dermaptera in the PAN Zoologiczny Instytut, Warszawa. Folia Entomologica Hungarica 32: 149-175

Steinmann H (1986) Dermaptera. Catadermaptera I. Das Tierreich 102: 1-343.

Steinmann H (1989a) Dermaptera. Catadermaptera II. Das Tierreich 105: 1-504.

Steinmann H (1989b) World Catalogue of Dermaptera. Kluwer Academic Publishers, Dordrecht, Netherlands, 934 pp.

Steinmann H (1990) Dermaptera. Eudermaptera I. Das Tierreich 106: 1-558.

Steinmann H (1993) Dermaptera. Eudermaptera II. Das Tierreich 108: 1-711.

Tatarnic NJ, Cassis G, Siva-Jothy MT (2014) Traumatic insemination in terrestrial arthropods. Annual Review of Entomology 59: 245-261. https://doi.org/10.1146/annurev-ento-011613-162111

Tworzydlo W, Lechowska-Liszka A, Kocarek P, Bilinski SM (2013) Morphology of the ovarioles and the mode of oogenesis of Arixenia esau support the inclusion of Arixeniina to the Eudermaptera. Zoologischer Anzeiger 252: 410-416. http://dx.doi.org/10.1016/j. jcz.2012.11.002

Zacher F (1911) Studien über die System der Protodermaptera. Zoologische Jahrbuecher Systematik 30: 303-340.

Zampaulo RA (2010) Diversidade de invertebrados cavernícolas na província espeleológica de Arcos, Pains e Doresópolis (MG): subsídios para a definição de áreas prioritárias para a conservação. Dissertation (Master degree in Applied Ecology). Universidade Federal de Lavras, Lavras, Minas Gerais, Brazil, 190 pp. 